\title{
Proceeding
}

Supplementary Issue: Spring Conferences of Sports Science. Costa Blanca Sports Science Events, 19-20 June 2020. Alicante, Spain.

\section{Ultrasound-guided collagen injections for treatment of plantar fasciopathy in runners: A pilot study and case series}

\author{
BRUNO CORRADO $\triangle$, ILENIA BONINI, DOMIZIANO TARANTINO, FELICE SIRICO \\ Department of Public Health, University Federico II of Naples, Italy
}

\begin{abstract}
Background. Plantar fasciopathy is a frequent source of foot pain in athletes, and it is caused by the degeneration of the proximal insertion of the plantar fascia, usually triggered by repetitive microtrauma. Type I porcine collagen was shown to enhance tendon repair in vitro, and collagen injections are currently used to treat different tendinopathies. The aim of this study is to verify the effectiveness of collagen injections on pain and function in runners with plantar fasciopathy. Methods. Runners, who have been suffering from plantar fasciopathy for at least 6 months, were treated with a series of 4 ultrasound-guided type I porcine collagen injections, at weekly intervals. The Visual Analogue Scale, American Orthopedic Foot and Ankle SocietyAnkle Hindfoot score and pressure algometry were used to verify the effects of collagen injections at 1-month and 3-month follow-up. Results. Compared to baseline, minor ( $p \geq .05)$ and major $(p \leq .001)$ improvements on pain and function were registered at 1-month and 3-month follow-up, respectively. Conclusion. This is the first study that evaluates the effectiveness of collagen injections in the treatment of plantar fasciopathy in runners. Despite the limitations of this study, the positive findings could represent the starting point for further clinical trials.

Keywords: Plantar fasciitis; Plantar fasciopathy; Chronic plantar fasciitis; Athletes; Runners; Collagen injections.

\section{Cite this article as:}

Corrado, B., Bonini, I., Tarantino, D., \& Sirico, F. (2020). Ultrasound-guided collagen injections for treatment of plantar fasciopathy in runners: A pilot study and case series. Journal of Human Sport and Exercise, 15(3proc), S793-S805. doi:https://doi.org/10.14198/ihse.2020.15.Proc3.30

Corresponding author. Department of Public Health, University Federico II of Naples, Via S. Pansini n.5, 80131 Naples, Italy. https://orcid.org/0000-0003-0990-3428

E-mail: bruno.corrado@unina.it

Supplementary Issue: Spring Conferences of Sports Science. Costa Blanca Sports Science Events, 19-20 June 2020. Alicante, Spain.

JOURNAL OF HUMAN SPORT \& EXERCISE ISSN 1988-5202

(c) Faculty of Education. University of Alicante

doi:10.14198/jhse.2020.15.Proc3.30
\end{abstract}




\section{INTRODUCTION}

Plantar fasciopathy (PF) is a musculoskeletal condition that affects the plantar fascia, which is a thick band made by connective tissue that runs from the calcaneal tuberosity forward to the heads of the metatarsal bones, helping to maintain the stability and the arch of the foot (Hormozi et al., 2011; Petraglia et al., 2017). The plantar fascia is divided into three cords, with the central one being the thickest and the most often injured (Meyer et al., 2018). PF was formerly known as "plantar fasciitis", but this term is obsolete, since inflammation is absent in this condition. Nowadays PF is considered a degenerative pathology, more similar to tendinopathy and to a chronic disease, which involves the site of the attachment of the plantar fascia at the medial tubercle of the calcaneus (Petraglia et al., 2017).

PF is a common cause of foot pain in adults, usually a plantar-medial heel pain, typically after a long weightbearing phase, and it usually worsens the patients' quality of life (Alrashidi et al., 2016; Irving et al., 2008). It has been reported that $10 \%$ of people may suffer from symptoms of PF during their lifetime (Monteagudo et al., 2018; Riddle et al., 2003). PF affects both sexes, ranging from sedentary individuals to athletes, with women being affected slightly more often than men (Orchard, 2012; Taunton et al., 2002). The peak incidence of PF occurs in people aged between 45 and 65 years (Riddle and Schappert, 2004). PF is experienced in both recreational and elite athletes and is reported in different sports (Orchard, 2012). A recent review concerning ankle and foot injuries in sport pointed out that PF is mainly reported in runners (Sobhani et al., 2013). The incidence of PF in runners ranges from 4.5 to $10 \%$, and represents the third most frequently experience running-related musculoskeletal injuries (Lopes et al., 2012). A recent prospective study analysed the novice running-related injuries, revealing that PF accounts for about $5 \%$ (Nielsen et al., 2014). In ultramarathon runners PF has an incidence of about 11\% (Hoffman and Krishnan, 2014). In runners, PF seems to be associated with overuse, training errors, and improper or excessively worn footwear (Rompe, 2009).

Diagnosis of PF is essentially clinical (Oliva et al., 2017). The cardinal symptom of PF is the intense and acute heel pain localized primarily where plantar fascia attaches to the anterior calcaneus (Petraglia et al., 2017). A runner typically reports a sensation of pain over the plantar aspect of the foot, typically worse with initial morning ambulation and improved during the course of a run, with worsening pain after discontinuation of activity (Tenforde et al., 2016). Foot stiffness and heel swelling are also present (Goff and Crawford, 2011). The Windlass test can be performed to confirm the diagnosis, although it has a low sensitivity (De Garceau et al., 2003).

In the case of uncertain diagnosis or when patient presents a persistent heel pain, instrumental analysis can be performed (Petraglia et al., 2017). Diagnostic imaging is recommended when patient suffers of persistent heel pain after 4-6 months of conservative approaches or in case of atypical symptoms or signs (Neufeld and Cerrato, 2008). Plain radiography, magnetic resonance imaging (MRI), diagnostic ultrasonography (US), nerve conduction study and bone scans can be carried out for differential diagnosis (Petraglia et al., 2017). US is a very useful, non-invasive, well-tolerated and reliable tool to confirm the diagnosis (Alrashidi et al., 2016; Lim et al., 2016). It can be used for follow-up and monitoring the improvement after initiation of therapy (Alrashidi et al., 2016). US features of PF include a thickened (> $4 \mathrm{~mm}$ ) and hypoechoic aponeurosis close to its calcaneal attachment (Elias et al., 2013). Shear wave elastography (SWE) allows quantitative assessment of the stiffness of the plantar fascia and can highlights the classic alterations of PF (Corrado et al., 2019; Schillizzi et al., 2020; Vola et al., 2018). Contrary to popular belief, recent studies have demonstrated no correlation between fascial thickness and degree of symptoms (Meyer et al., 2018). 
The crucial aims of PF management are the reduction of pain, the improvement of quality of life, including both the return to daily physical activity and physical fitness (; (Petraglia et al., 2017). Around 90\% of patients with PF will find that their symptoms resolve within 12 months with conservative treatment (Crawford and Thomson, 2003), but about one tenth of cases may fail to respond to it. The first level of treatment would include the use of non-steroidal anti-inflammatory drugs (NASAIDs), specific physical exercises (such as stretching of the plantar fascia), foot insoles, night splints, ice massage, and patient's instructions to lose weight, activity modifications, and not to use flat shoes or walk barefoot (Akınoğlu and Köse, 2018; Celik et al., 2016; Cinar et al., 2018; Huffer et al., 2017; Lim et al., 2016, 2016; Montesano et al., 2020; Oliva et al., 2017; Palermi et al., 2020; Sirico et al., 2018). Other treatment options are local injections of corticosteroids (CSs) (Gurcay et al., 2017), anaesthetic, and botulinum toxin (Ahmad et al., 2017); extracorporeal shock wave therapy (Corrado et al., 2019; Hsu et al., 2018; Reilly et al., 2018); ultrasound scanning; radiofrequency ablation (Akınoğlu and Köse, 2018; Ozan et al., 2017); cryopreserved human amniotic membrane injections (Hanselman et al., 2015); prolotherapy (Kim and Lee, 2014; Ryan et al., 2009); ozone injections (Bahrami et al., 2019); hyaluronic acid injections (Kumai et al., 2018); platelet-rich plasma injections (PRP) (Chen et al., 2019; Franceschi et al., 2014; Singh et al., 2017; Sirico et al., 2017; Soraganvi et al., 2019); and surgical, such as endoscopic release (Al-Ashhab et al., 2018; Bernhard et al., 2018; Oliva et al., 2017). However, as yet, there is no consensus regarding the optimal treatment method (Corrado et al., 2019, Eftekharsadat et al., 2016; Kiter et al., 2006; Say et al., 2014).

To our knowledge, only one study by Kim et al. (Kim et al., 2016) explored the effects of collagen injections for PF after unsuccessful conservative treatment with NSAIDs, night splints, and stretching exercises for at least 3 months, reporting an increased tissue elasticity after treatment. Given the degenerative nature of PF, that encompasses collagen degeneration, the rationale behind the use of collagen injections is that collagen is a major extracellular matrix component in tendons and ligaments, and it contributes to the entrapment, local storage, and delivery of growth factors and cytokines. Collagen also plays an important role in organ development, wound healing, and tissue repair (Hay, 1981). Injectable collagen is used to treat different tendinopathies (Corrado et al., 2020; Corrado et al., 2019), because of its ability to stimulate synthesis, maturation and secretion of endogenous type I collagen (Randelli et al., 2018).

The aims of this prospective pilot study and case series are: (a) to evaluate the effectiveness of US-guided collagen injections in the treatment of PF in a group of runners, and (b) to examine the feasibility of such an intervention that is intended to be used in a larger scale and higher quality studies.

No studies on the effectiveness of collagen injections in treating PF in runners have been published to date.

\section{MATERIALS AND METHODS}

This is a prospective observational pilot study carried out at the Federico II University Hospital of Naples, Italy. The subjects of our study were all outpatients, enrolled from September 2019 to November 2019. The patients were non-professional marathon runners who have been suffering from PF for at least 6 months. All patients underwent US and X-ray before the enrolment.

The inclusion criteria were: age > 18 years, pain over the plantar aspect of the foot (typically worse with initial morning ambulation and improved while running), sharp pain elicited by palpation of the medial plantar calcaneal region, a positive Windlass test, US evidence of increased plantar fascia thickness, and lack of therapy in the last 6 months. 
The exclusion criteria were: previous foot and ankle surgery, inflammatory arthritis, X-ray evidence of heel spur, and previous fractures, bone tumours or osteonecrosis of the ankle and foot.

After a full and clear description of the study protocol, all the enrolled patients were invited to sign the informed consent. The study was carried out in accordance with the principles of the Declaration of Helsinki and met the ethical standards of the local ethics committee.

Ten patients were enrolled ( 7 males and 3 females), with an average age of $34 \pm 8$ years. Regarding the treatment, four US-guided injections of $2 \mathrm{ml}$ porcine type I collagen were planned once a week. All injections were performed by a single physician with over ten years of experience. There is strong evidence that the accuracy of US guidance is greater than that of palpation guidance (Hall, 2013). Injections were performed with the patients lying face down on the examination table. A 22-gauge needle was inserted with a medial approach under US guidance, aligned to the long axis of the US transducer. The needle was directed anteriorly to the insertion of the plantar fascia on the calcaneal bone, in the region of the maximal thickness of the fascia. When the tip of the needle was seen in the correct position, then collagen was slowly injected.

Patients were invited to not rest after each injection, but only to avoid foot and ankle overloading for 24 hours. Patients were advised to interrupt their sporting activities during the treatment and until the last follow-up. No other treatment was associated with collagen injections.

Patients were evaluated at the time of enrolment (T0), one month (T1) and three months (T2) after the last injection. Pain was assessed using the $10 \mathrm{~cm}$-Visual Analogue Scale (VAS) and the pressure algometry. Assessment of function was conducted using the Italian version of the American Orthopedic Foot and Ankle Society - Ankle-Hindfoot (AOFAS-AH) score.

Pressure algometry is a semiquantitative method used to evaluate the pain threshold in tissues. The pressure algometry has been validated to determine pain threshold (Walton et al., 2011; Ylinen et al., 2007), and it has been found repeatable and stable (Frank et al., 2013). The pressure algometer used in this study was a Force Dial $^{T M}$ FDK 20 (Wagner Instruments, Greenwich USA). The pressure was measured in kilogram per square centimetre $\left(\mathrm{Kg} / \mathrm{cm}^{2}\right)$. The measurement was conducted on the most sensitive point of the plantar fascia. The algometer contact head was aligned perpendicularly to the skin and the pressure gradually increased until the patient reported pain (i.e. pain tolerance). This process was repeated three times at the same point on the plantar fascia, then an average of the three readings was recorded. Higher algometer scores indicated greater pressure threshold and less tenderness, and vice versa.

The AOFAS-AH score comprises nine questions and covers three categories: pain (40 points), function (50 points) and alignment (10 points), for a total of 100 points. Although it has yet to be validated, the AOFAS$\mathrm{AH}$ is one of the most widely-used score in clinical studies concerning ankle and foot, and it remains in use at a substantially higher rate than other scales that have been validated (Leigheb et al., 2016).

Results were calculated as mean and standard deviation. Statistical significance was analysed by one-way nonparametric ANOVA (Kruskal Wallis test). The confidence interval was established at $95 \%(p<.05)$. Statistical analysis was performed using IBM SPSS version 20 for Windows. 


\section{RESULTS}

Means and standard deviations of VAS, pressure algometry, and AOFAS-AH are listed in Table 1.

Table 1. Means and standard deviations of VAS, pressure algometry, and AOFAS-AH at different follow-up times.

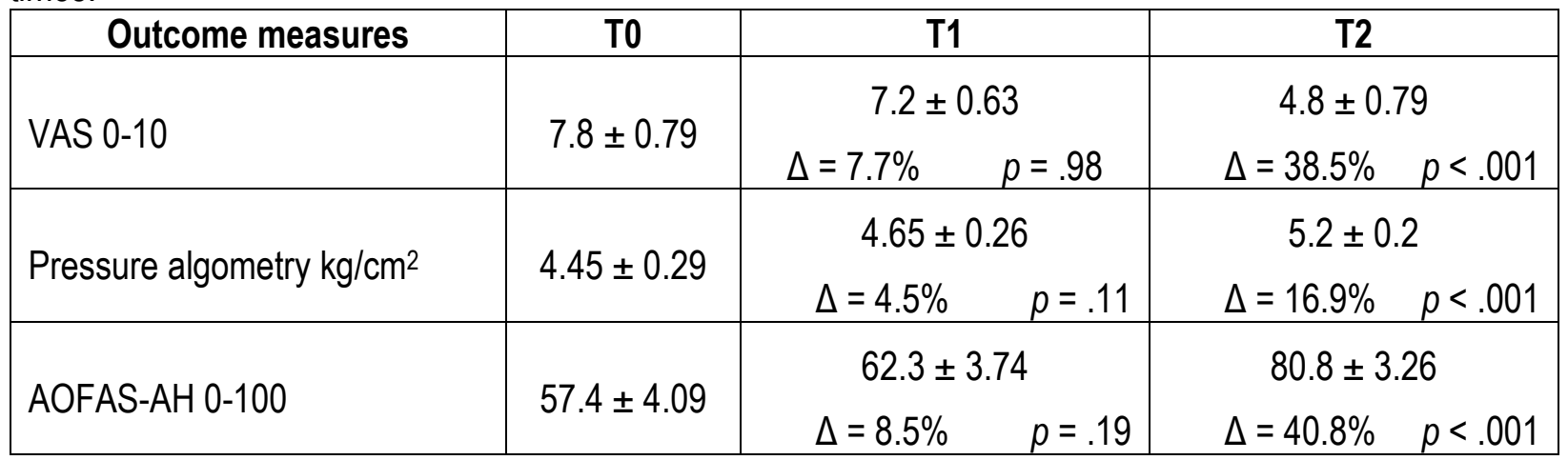

Note: VAS = Visual Analogue Scale; AOFAS-HF = American Orthopedic Foot Ankle Society - Hind Foot; $\Delta=$ relative delta.

At the baseline, mean scores of VAS, pressure algometry, and AOFAS-AH were $7.8,4.45 \mathrm{Kg} / \mathrm{cm}^{2}$, and 57.4 , respectively.

At 1-month follow up, evaluation of VAS and pressure algometry showed a not statistically significant improvement in pain relief (mean VAS score $=7.2$; mean algometry score $=4.65 \mathrm{Kg} / \mathrm{cm}^{2}$ ). Regarding the improvement of function, the average AOFAS-AH at T1 was 63.3, and even in this case the difference was not statistically significant $(p=.19)$.

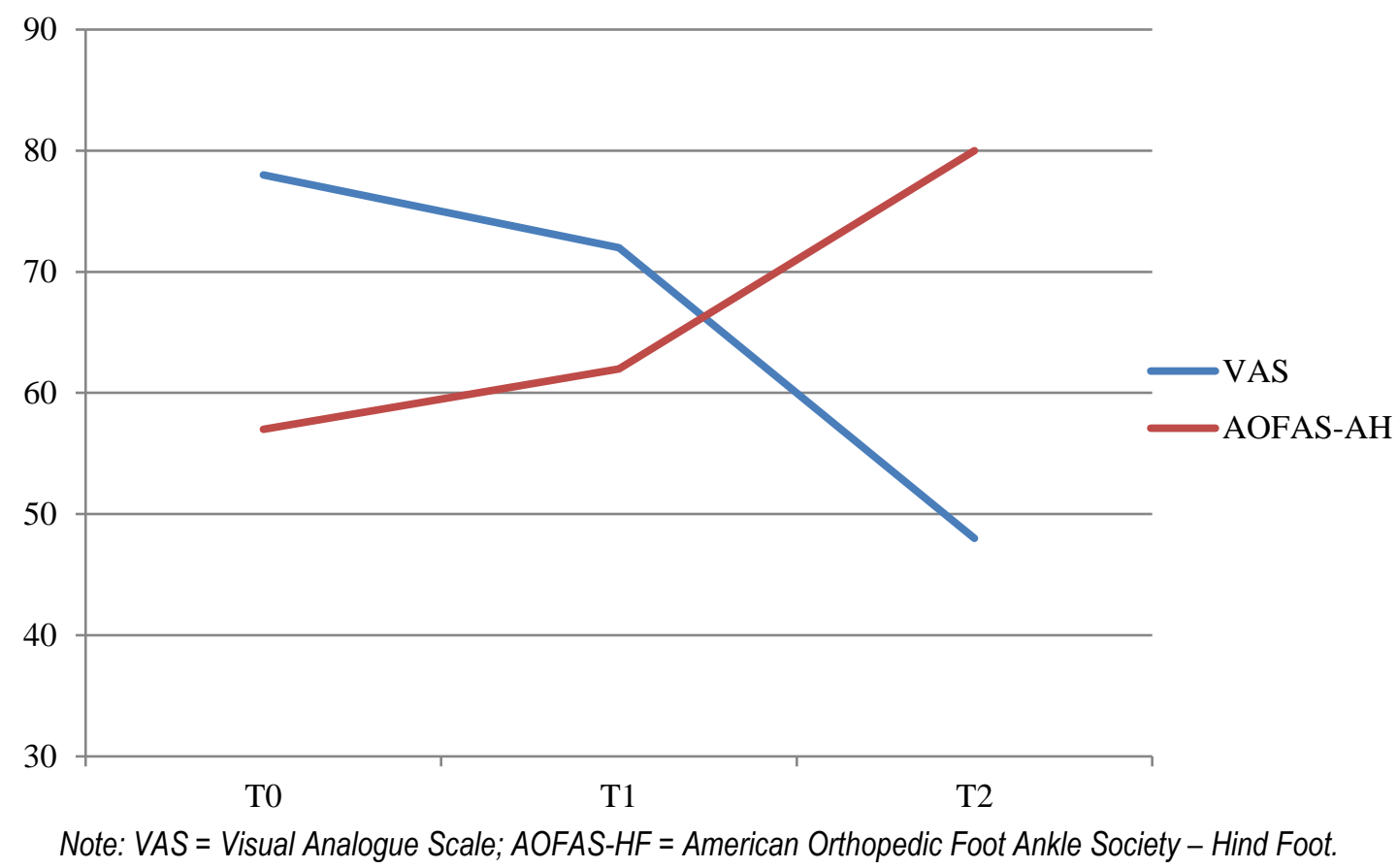

Figure 1. Trends of VAS and AOFAS-AH over time. 
At 3-month follow up, improvement in pain and function became greater and statistically significant. The average scores of VAS, pressure algometry, and AOFAS-AH were $4.8,5.2 \mathrm{Kg} / \mathrm{cm}^{2}$, and 80.8 , respectively $(p$ $<.001$ ). Trends of VAS and AOFAS-AH over time are shown in Figure 1.

No adverse event was reported after collagen injections, except for some cases of burning sensation at the injection site which resolved spontaneously in a few hours.

\section{DISCUSSION}

PF is a common cause of heel pain and foot impairment in both élite and recreational athletes. Different approaches are available for the treatment of PF, either conservative and surgical. Approximately $90 \%$ of patients with PF can be successfully treated without surgery (Monteagudo et al., 2018).

Injections are one of the several conservative interventions used to treat PF, with CSs and PRP being the most commonly administered drugs.

Several studies showed that CSs injections provide pain relief in the short term, but they do not provide a long-lasting effect (no more than one month) and could carry some risk of complications such as plantar fascia rupture and plantar fat pad atrophy (David et al., 2017; Tatli and Kapasi, 2009).

PRP injections seem to be a safer modality when compared to CSs injections, and it was suggested that PRP affects collagen catabolism and irregular vascularization in chronic PF (Monto, 2013). A recent systematic review pointed out that PRP injections were associated with improved pain and function at 3month follow-up (Singh et al., 2017). However, adverse event rates and costs of PRP injections for the treatment of PF have not been properly analysed.

To our knowledge, in the current scientific literature only one study by Kim et al. reported the outcomes of collagen injections for treating PF, but not in athletes (Kim et al., 2016). Kim and colleagues evaluated the effectiveness of a series of three collagen injections in the treatment of PF using US elastography. Patients showed significantly increased strain ratios in their calcaneal insertions after collagen injections, proving the regenerative effect of such a therapy (Kim et al., 2016).

In our pilot study, we wanted to evaluate the effectiveness of collagen injection therapy in a group of ten runners affected by chronic PF (four injections of type I porcine collagen, once a week).

A direct comparison of results is possible only with the study by Kim et al., even if the assessment tool is a little bit different. In the study by Kim et al., the pain relief was assessed using the $100 \mathrm{~mm}$-VAS three months after the last collagen injection (Kim et al., 2016). The mean $100 \mathrm{~mm}$-VAS scores were, before and after treatment, respectively 71.8 and 43.9 . A $38.9 \%$ reduction of the pain score was registered. In our study, the mean VAS scores were 7.8 and 4.8 at T0 and T2 (3-month follow-up), respectively. We observed a $38.5 \%$ reduction of the pain after treatment. Therefore, the results between our study and the one by Kim and colleagues are totally comparable (M. Kim et al., 2016).

Our results can be also compared with those of different injectable therapies frequently used for the management of PF. 
Jain et al. aimed to compare the efficacy of PRP to traditional CS injection in the treatment of chronic PF at three, six and twelve months after injection (Jain et al., 2015). Patients were assessed using the $10 \mathrm{~cm}$-VAS for pain and the AOFAS-AH score for function.

The CSs group had a pre-treatment average score of 8.27 and 56.70 for VAS and AOFAS-AH respectively, while the PRP group had a pre-treatment average score of 8.30 e 58.63 for VAS and AOFAS-AH respectively. At three months post-treatment, the VAS and AOFAS-AH average scores improved, respectively, to 2.83 and 86.37 as regards to the CS group, and improved, respectively, to 3.50 and 83.70 as regards to the PRP group.

Comparing our results with those achieved by Jain et al., we can state that collagen injections at 3-month follow-up reach the same pain relief and function restoration similar to those of PRP injections (Jain et al., 2015).

Mahindra et al. compared the effects of PRP and CSs injections in the treatment of chronic PF. Patients were assessed using the $10 \mathrm{~cm}$-VAS for pain and the AOFAS-AH score before injection, at three weeks, and at 3month follow-up (Mahindra et al., 2016).

Mean VAS score in the PRP and CSs groups decreased, respectively, from 7.44 and 7.72 at the pre-injection time to 3.76 and 2.84 at 3-week follow-up and, respectively, to 2.52 and 3.64 at 3-month final follow-up. Mean AOFAS-AH score in the PRP and CSs groups improved, respectively, from 51.56 and 55.72 at the preinjection time to 83.92 and 86.6 at 3-week follow-up and, respectively, to 88.24 and 81.32 at the final 3-month follow-up. The authors concluded that PRP injection is as effective or more effective than CSs injection in treating chronic PF.

In comparison to our findings, we can state that CSs are slightly more effective for pain relief and functional improvement in the short term compared to PRP and much more effective compared to collagen but, at an intermediate term, PRP and collagen are more effective than CSs, especially regarding the disability reduction.

Summarizing, CSs injection resulted in short-term benefit (no more than 1 month) with an associated increased risk of rupture of the plantar fascia and fat pad atrophy especially if frequently repeated, whereas PRP injections were associated with improved pain and function at 3-month follow-up even if no clear information regarding adverse event rates or costs have been provided until now.

In our pilot study, adverse events were not observed neither during nor after the treatment, and the costbenefit ratio was judged positive by the enrolled patients.

The preliminary findings of our study let us suppose that collagen injections are useful for treating PF. Since collagen is a structural protein of the plantar fascia, injectable collagen works not just healing, but also restoring the tissue's native function. Endogenous collagen synthesis, maturation, and secretion are also stimulated by injectable collagen, thus favouring plantar fascia repair. The effectiveness at the intermediate term and the lack of side effects could be explained on the basis of the above-mentioned reasons.

The present study has some limitations: (a) a small sample, (b) the lack of a control group, and (c) the short follow-up time. However, it should be highlighted that this is a pilot study and that is, to our knowledge, the only study on the effectiveness of collagen injection therapy for PF in athletes. 
In conclusion, our pilot study pointed out that a series of four type I porcine collagen US-guided injections, at weekly intervals, is able to reduce significantly pain symptoms and to improve function in a group of 10 runners with PF at 3-month follow-up.

Higher quality studies with a greater number of patients are needed to confirm our preliminary studies and draw more definitive conclusions on the role of collagen injections in the management of PF.

\section{REFERENCES}

Ahmad, J., Ahmad, S. H., \& Jones, K. (2017). Treatment of Plantar Fasciitis With Botulinum Toxin. Foot \& Ankle International, 38(1), 1-7. https://doi.org/10.1177/1071100716666364

Akınoğlu, B., \& Köse, N. (2018). A comparison of the acute effects of radial extracorporeal shockwave therapy, ultrasound therapy, and exercise therapy in plantar fasciitis. Journal of Exercise Rehabilitation, 14(2), 306-312. https://doi.org/10.12965/jer.1836048.024

Al-Ashhab, M. E., Elbegawy, H. E.-D. A., \& Hasan, H. A. A. (2018). Endoscopic Plantar Fasciotomy Through Two Medial Portals for the Treatment of Recalcitrant Plantar Fasciopathy. The Journal of Foot and Ankle Surgery: Official Publication of the American College of Foot and Ankle Surgeons, 57(2), 264-268. https://doi.org/10.1053/j.jfas.2017.09.004

Alrashidi, Y., Barg, A., Kampmann, M., \& Valderrabano, V. (2016). Plantar Fasciitis in Sport. In V. Valderrabano \& M. Easley (A c. Di), Foot and Ankle Sports Orthopaedics (pagg. 201-207). Springer International Publishing. https://doi.org/10.1007/978-3-319-15735-1_21

Bahrami, M. H., Raeissadat, S. A., Barchinejad, M., Elyaspour, D., \& Rahimi-Dehgolan, S. (2019). Local ozone (O2-O3) versus corticosteroid injection efficacy in plantar fasciitis treatment: A double-blinded RCT. Journal of Pain Research, 12, 2251-2259. https://doi.org/10.2147/JPR.S202045

Bernhard, K., Ng, A., Kruse, D., \& Stone, P. A. (2018). Surgical Treatment of Bone Marrow Lesion Associated with Recurrent Plantar Fasciitis: A Case Report Describing an Innovative Technique Using Subchondroplasty®. The Journal of Foot and Ankle Surgery: Official Publication of the American College of Foot and Ankle Surgeons, 57(4), 811-815. https://doi.org/10.1053/j.jfas.2017.11.012

Celik, D., Kuş, G., \& Sırma, S. Ö. (2016). Joint Mobilization and Stretching Exercise vs Steroid Injection in the Treatment of Plantar Fasciitis: A Randomized Controlled Study. Foot \& Ankle International, 37(2), 150-156. https://doi.org/10.1177/1071100715607619

Chen, Y.-J., Wu, Y.-C., Tu, Y.-K., Cheng, J.-W., Tsai, W.-C., \& Yu, T.-Y. (2019). Autologous BloodDerived Products Compared With Corticosteroids for Treatment of Plantar Fasciopathy: A Systematic Review and Meta-Analysis. American Journal of Physical Medicine \& Rehabilitation, 98(5), 343-352. https://doi.org/10.1097/PHM.0000000000001070

Cinar, E., Saxena, S., \& Uygur, F. (2018). Combination Therapy Versus Exercise and Orthotic Support in the Management of Pain in Plantar Fasciitis: A Randomized Controlled Trial. Foot \& Ankle International, 39(4), 406-414. https://doi.org/10.1177/1071100717747590

Corrado, B., Albano, M., Caprio, M. G., Di Luise, C., Sansone, M., Servodidio, V., Russo, S., Vallone, G., Vola, E. A., \& lammarrone, C. S. (2019). Usefulness of point shear wave elastography to assess the effects of extracorporeal shockwaves on spastic muscles in children with cerebral palsy: An uncontrolled experimental study. Muscles, Ligaments \& Tendons Journal (MLTJ), 9(1), 124-130. https://doi.org/10.32098/mlti.01.2019.04

Corrado, B, Bonini, I., Chirico, V., Filippini, E., Liguori, L., Magliulo, G., Mazzuoccolo, G., Rosano, N., \& Gisonni, P. (2020). Ultrasound-guided collagen injections in the treatment of supraspinatus 
tendinopathy: A case series pilot study. Journal of Biological Regulators and Homeostatic Agents, 34(3-S2), 33-39.

Corrado, B., Mazzuoccolo, G., Liguori, L., Chirico, V. A., Costanzo, M., Bonini, I., Bove, G., \& Curci, L. (2019). Treatment of Lateral Epicondylitis with Collagen Injections: A Pilot Study. Muscle Ligaments and Tendons Journal, 09(04), 584. https://doi.org/10.32098/mltj.04.2019.14

Corrado, Bruno, Ciardi, G., Fortunato, L., \& lammarrone, C. S. (2019). Burnout syndrome among Italian physiotherapists: A cross-sectional study. European Journal of Physiotherapy, 21(4), 240-245. https://doi.org/10.1080/21679169.2018.1536765

Corrado, Bruno, Di Luise Carla, \& Servodio lammarrone Clemente. (2019). Management of Muscle Spasticity in Children with Cerebral Palsy by Means of Extracorporeal Shockwave Therapy: A Systematic Review of the Literature. 1-7-7. https://doi.org/10.1080/17518423.2019.1683908

Crawford, F., \& Thomson, C. (2003). Interventions for treating plantar heel pain. The Cochrane Database of Systematic Reviews, 3, CD000416. https://doi.org/10.1002/14651858.CD000416

David, J. A., Sankarapandian, V., Christopher, P. R., Chatterjee, A., \& Macaden, A. S. (2017). Injected corticosteroids for treating plantar heel pain in adults. The Cochrane Database of Systematic Reviews, 6, CD009348. https://doi.org/10.1002/14651858.CD009348.pub2

De Garceau, D., Dean, D., Requejo, S. M., \& Thordarson, D. B. (2003). The association between diagnosis of plantar fasciitis and Windlass test results. Foot \& Ankle International, 24(3), 251-255. https://doi.org/10.1177/107110070302400309

Eftekharsadat, B., Babaei-Ghazani, A., \& Zeinolabedinzadeh, V. (2016). Dry needling in patients with chronic heel pain due to plantar fasciitis: A single-blinded randomized clinical trial. Medical Journal of the Islamic Republic of Iran, 30, 401.

Elias, D. A., Carne, A., Bethapudi, S., Engebretsen, L., Budgett, R., \& O'Connor, P. (2013). Imaging of plantar fascia and Achilles injuries undertaken at the London 2012 Olympics. Skeletal Radiology, 42(12), 1645-1655. https://doi.org/10.1007/s00256-013-1689-1

Franceschi, F., Papalia, R., Franceschetti, E., Paciotti, M., Maffulli, N., \& Denaro, V. (2014). Platelet-rich plasma injections for chronic plantar fasciopathy: A systematic review. British Medical Bulletin, 112(1), 83-95. https://doi.org/10.1093/bmb/ldu025

Frank, L., McLaughlin, P., \& Vaughan, B. (2013). The repeatability of pressure algometry in asymptomatic individuals over consecutive days. International Journal of Osteopathic Medicine, 16(3), 143-152. https://doi.org/10.1016/i.ijosm.2012.10.004

Goff, J. D., \& Crawford, R. (2011). Diagnosis and Treatment of Plantar Fasciitis. American Family Physician, 84(6), 676-682.

Gurcay, E., Kara, M., Karaahmet, O. Z., Ata, A. M., Onat, Ş. Ş., \& Özçakar, L. (2017). Shall We Inject Superficial or Deep to the Plantar Fascia? An Ultrasound Study of the Treatment of Chronic Plantar Fasciitis. The Journal of Foot and Ankle Surgery: Official Publication of the American College of Foot and Ankle Surgeons, 56(4), 783-787. https://doi.org/10.1053/i.jfas.2017.03.004

Hall, M. M. (2013). The accuracy and efficacy of palpation versus image-guided peripheral injections in sports medicine. Current Sports Medicine Reports, 12(5), 296-303. https://doi.org/10.1097/01.CSMR.0000434103.32478.36

Hanselman, A. E., Tidwell, J. E., \& Santrock, R. D. (2015). Cryopreserved human amniotic membrane injection for plantar fasciitis: A randomized, controlled, double-blind pilot study. Foot \& Ankle International, 36(2), 151-158. https://doi.org/10.1177/1071100714552824

Hay, E. D. (1981). Extracellular matrix. The Journal of Cell Biology, 91(3 Pt 2), 205s-223s. https://doi.org/10.1083/jcb.91.3.205s 
Hoffman, M. D., \& Krishnan, E. (2014). Health and Exercise-Related Medical Issues among 1,212 Ultramarathon Runners: Baseline Findings from the Ultrarunners Longitudinal TRAcking (ULTRA) Study. PLoS ONE, 9(1). https://doi.org/10.1371/journal.pone.0083867

Hormozi, J., Lee, S., \& Hong, D. K. (2011). Minimal invasive percutaneous bipolar radiofrequency for plantar fasciotomy: A retrospective study. The Journal of Foot and Ankle Surgery: Official Publication of the American College of Foot and Ankle Surgeons, 50(3), 283-286. https://doi.org/10.1053/i.jfas.2011.02.007

Hsu, W.-H., Yu, P.-A., Lai, L.-J., Chen, C.-L., Kuo, L.-T., \& Fan, C.-H. (2018). Effect of Extracorporeal Shockwave Therapy on Passive Ankle Stiffness in Patients With Plantar Fasciopathy. The Journal of Foot and Ankle Surgery: Official Publication of the American College of Foot and Ankle Surgeons, 57(1), 15-18. https://doi.org/10.1053/j.jfas.2017.05.038

Huffer, D., Hing, W., Newton, R., \& Clair, M. (2017). Strength training for plantar fasciitis and the intrinsic foot musculature: A systematic review. Physical Therapy in Sport: Official Journal of the Association of Chartered Physiotherapists in Sports Medicine, 24, 44-52. https://doi.org/10.1016/j.ptsp.2016.08.008

Irving, D. B., Cook, J. L., Young, M. A., \& Menz, H. B. (2008). Impact of chronic plantar heel pain on health-related quality of life. Journal of the American Podiatric Medical Association, 98(4), 283-289. https://doi.org/10.7547/0980283

Jain, K., Murphy, P. N., \& Clough, T. M. (2015). Platelet rich plasma versus corticosteroid injection for plantar fasciitis: A comparative study. Foot (Edinburgh, Scotland), 25(4), 235-237. https://doi.org/10.1016/j.foot.2015.08.006

Kim, E., \& Lee, J. H. (2014). Autologous platelet-rich plasma versus dextrose prolotherapy for the treatment of chronic recalcitrant plantar fasciitis. PM \& R: The Journal of Injury, Function, and Rehabilitation, 6(2), 152-158. https://doi.org/10.1016/j.pmrj.2013.07.003

Kim, M., Choi, Y. S., You, M.-W., Kim, J. S., \& Young, K. W. (2016). Sonoelastography in the Evaluation of Plantar Fasciitis Treatment: 3-Month Follow-Up After Collagen Injection. Ultrasound Quarterly, 32(4), 327-332. https://doi.org/10.1097/RUQ.0000000000000233

Kiter, E., Celikbas, E., Akkaya, S., Demirkan, F., \& Kiliç, B. A. (2006). Comparison of injection modalities in the treatment of plantar heel pain: A randomized controlled trial. Journal of the American Podiatric Medical Association, 96(4), 293-296. https://doi.org/10.7547/0960293

Kumai, T., Samoto, N., Hasegawa, A., Noguchi, H., Shiranita, A., Shiraishi, M., Ikeda, S., Sugimoto, K., Tanaka, Y., \& Takakura, Y. (2018). Short-term efficacy and safety of hyaluronic acid injection for plantar fasciopathy. Knee Surgery, Sports Traumatology, Arthroscopy: Official Journal of the ESSKA, 26(3), 903-911. https://doi.org/10.1007/s00167-017-4467-0

Leigheb, M., Janicka, P., Andorno, S., Marcuzzi, A., Magnani, C., \& Grassi, F. (2016). Italian translation, cultural adaptation and validation of the «American Orthopaedic Foot and Ankle Society's (AOFAS) ankle-hindfoot scale». Acta Bio-Medica: Atenei Parmensis, 87(1), 38-45.

Lim, A. T., How, C. H., \& Tan, B. (2016). Management of plantar fasciitis in the outpatient setting. Singapore Medical Journal, 57(4), 168-171. https://doi.org/10.11622/smedj.2016069

Lopes, A. D., Hespanhol Júnior, L. C., Yeung, S. S., \& Costa, L. O. P. (2012). What are the main runningrelated musculoskeletal injuries? A Systematic Review. Sports Medicine (Auckland, N.Z.), 42(10), 891-905. https://doi.org/10.1007/BF03262301

Mahindra, P., Yamin, M., Selhi, H. S., Singla, S., \& Soni, A. (2016). Chronic Plantar Fasciitis: Effect of Platelet-Rich Plasma, Corticosteroid, and Placebo. Orthopedics, 39(2), e285-289. https://doi.org/10.3928/01477447-20160222-01 
Meyer, N. B., Jacobson, J. A., Kalia, V., \& Kim, S. M. (2018). Musculoskeletal ultrasound: Athletic injuries of the lower extremity. Ultrasonography (Seoul, Korea), 37(3), 175-189. https://doi.org/10.14366/usg.18013

Monteagudo, M., de Albornoz, P. M., Gutierrez, B., Tabuenca, J., \& Álvarez, I. (2018). Plantar fasciopathy: A current concepts review. EFORT Open Reviews, 3(8), 485-493. https://doi.org/10.1302/2058-5241.3.170080

Montesano, P., Daniele, M., Maurizio Di Silvestro, Giulia, C., Tafuri, D., \& Mazzeo, F. (2020). Effects of combined training program, controlled diet and drugs on middle-distance amateur runners: A Pilot Study. 13(1), 17-22.

Monto, R. R. (2013). Platelet-rich plasma and plantar fasciitis. Sports Medicine and Arthroscopy Review, 21(4), 220-224. https://doi.org/10.1097/JSA.0b013e318297fa8d

Neufeld, S. K., \& Cerrato, R. (2008). Plantar fasciitis: Evaluation and treatment. The Journal of the American Academy of Orthopaedic Surgeons, 16(6), 338-346. https://doi.org/10.5435/00124635200806000-00006

Nielsen, R. O., Rønnow, L., Rasmussen, S., \& Lind, M. (2014). A prospective study on time to recovery in 254 injured novice runners. PloS One, 9(6), e99877. https://doi.org/10.1371/journal.pone.0099877

Oliva, F., Piccirilli, E., Tarantino, U., \& Maffulli, N. (2017). Percutaneous release of the plantar fascia. New surgical procedure. Muscles, Ligaments and Tendons Journal, 7(2), 338-340. https://doi.org/10.11138/mlti/2017.7.2.338

Orchard, J. (2012). Plantar fasciitis. BMJ (Clinical Research Ed.), 345, e6603. https://doi.org/10.1136/bmi.e6603

Ozan, F., Koyuncu, Ş., Gürbüz, K., Öncel, E. S., \& Altay, T. (2017). Radiofrequency Thermal Lesioning and Extracorporeal Shockwave Therapy: A Comparison of Two Methods in the Treatment of Plantar Fasciitis. Foot \& Ankle Specialist, 10(3), 204-209. https://doi.org/10.1177/1938640016675408

Palermi, S., Sacco, A. M., Belviso, I., Romano, V., Montesano, P., Corrado, B., \& Sirico, F. (2020). Guidelines for Physical Activity-A Cross-Sectional Study to Assess Their Application in the General Population. Have We Achieved Our Goal? International Journal of Environmental Research and Public Health, 17(11). https://doi.org/10.3390/ijerph17113980

Petraglia, F., Ramazzina, I., \& Costantino, C. (2017). Plantar fasciitis in athletes: Diagnostic and treatment strategies. A systematic review. Muscles, Ligaments and Tendons Journal, 7(1), 107-118. https://doi.org/10.11138/mlti/2017.7.1.107

Randelli, F., Menon, A., Giai Via, A., Mazzoleni, M. G., Sciancalepore, F., Brioschi, M., \& Gagliano, N. (2018). Effect of a Collagen-Based Compound on Morpho-Functional Properties of Cultured Human Tenocytes. Cells, 7(12). https://doi.org/10.3390/cells7120246

Reilly, J. M., Bluman, E., \& Tenforde, A. S. (2018). Effect of Shockwave Treatment for Management of Upper and Lower Extremity Musculoskeletal Conditions: A Narrative Review. PM \& R: The Journal of Injury, Function, and Rehabilitation, 10(12), 1385-1403. https://doi.org/10.1016/i.pmri.2018.05.007

Riddle, D. L., Pulisic, M., Pidcoe, P., \& Johnson, R. E. (2003). Risk factors for Plantar fasciitis: A matched case-control study. The Journal of Bone and Joint Surgery. American Volume, 85(5), 872-877. https://doi.org/10.2106/00004623-200305000-00015

Riddle, D. L., \& Schappert, S. M. (2004). Volume of ambulatory care visits and patterns of care for patients diagnosed with plantar fasciitis: A national study of medical doctors. Foot \& Ankle International, 25(5), 303-310. https://doi.org/10.1177/107110070402500505

Rompe, J. D. (2009). Plantar fasciopathy. Sports Medicine and Arthroscopy Review, 17(2), 100-104. https://doi.org/10.1097/JSA.0b013e3181a3d60e

Ryan, M. B., Wong, A. D., Gillies, J. H., Wong, J., \& Taunton, J. E. (2009). Sonographically guided intratendinous injections of hyperosmolar dextrose/lidocaine: A pilot study for the treatment of chronic 
plantar fasciitis. British Journal of Sports Medicine, 43(4), 303-306. https://doi.org/10.1136/bjsm.2008.050021

Say, F., Gürler, D., İnkaya, E., \& Bülbül, M. (2014). Comparison of platelet-rich plasma and steroid injection in the treatment of plantar fasciitis. Acta Orthopaedica Et Traumatologica Turcica, 48(6), 667-672. https://doi.org/10.3944/AOTT.2014.13.0142

Schillizzi, G., Alviti, F., D'Ercole, C., Elia, D., Agostini, F., Mangone, M., Paoloni, M., Bernetti, A., Pacini, P., Polti, G., Minafra, P., \& Cantisani, V. (2020). Evaluation of plantar fasciopathy shear wave elastography: A comparison between patients and healthy subjects. Journal of Ultrasound. https://doi.org/10.1007/s40477-020-00474-7

Singh, P., Madanipour, S., Bhamra, J. S., \& Gill, I. (2017). A systematic review and meta-analysis of platelet-rich plasma versus corticosteroid injections for plantar fasciopathy. International Orthopaedics, 41(6), 1169-1181. https://doi.org/10.1007/s00264-017-3470-x

Sirico, F., Miressi, S., Castaldo, C., Spera, R., Montagnani, S., Di Meglio, F., \& Nurzynska, D. (2018). Habits and beliefs related to food supplements: Results of a survey among Italian students of different education fields and levels. PloS One, 13(1), e0191424. https://doi.org/10.1371/journal.pone.0191424

Sirico, F., Ricca, F., DI Meglio, F., Nurzynska, D., Castaldo, C., Spera, R., \& Montagnani, S. (2017). Local corticosteroid versus autologous blood injections in lateral epicondylitis: Meta-analysis of randomized controlled trials. European Journal of Physical and Rehabilitation Medicine, 53(3), 483491. https://doi.org/10.23736/S1973-9087.16.04252-0

Sobhani, S., Dekker, R., Postema, K., \& Dijkstra, P. U. (2013). Epidemiology of ankle and foot overuse injuries in sports: A systematic review. Scandinavian Journal of Medicine \& Science in Sports, 23(6), 669-686. https://doi.org/10.1111/j.1600-0838.2012.01509.x

Soraganvi, P., Nagakiran, K. V., Raghavendra-Raju, R. P., Anilkumar, D., Wooly, S., Basti, B. D., \& Janakiraman, P. (2019). Is Platelet-rich Plasma Injection more Effective than Steroid Injection in the Treatment of Chronic Plantar Fasciitis in Achieving Long-term Relief? Malaysian Orthopaedic Journal, 13(3), 8-14. https://doi.org/10.5704/MOJ.1911.002

Tatli, Y. Z., \& Kapasi, S. (2009). The real risks of steroid injection for plantar fasciitis, with a review of conservative therapies. Current Reviews in Musculoskeletal Medicine, 2(1), 3-9. https://doi.org/10.1007/s12178-008-9036-1

Taunton, J. E., Ryan, M. B., Clement, D. B., McKenzie, D. C., Lloyd-Smith, D. R., \& Zumbo, B. D. (2002). A retrospective case-control analysis of 2002 running injuries. British Journal of Sports Medicine, 36(2), 95-101. https://doi.org/10.1136/bjsm.36.2.95

Tenforde, A. S., Yin, A., \& Hunt, K. J. (2016). Foot and Ankle Injuries in Runners. Physical Medicine and Rehabilitation Clinics of North America, 27(1), 121-137. https://doi.org/10.1016/j.pmr.2015.08.007

Vola, E. A., Albano, M., Di Luise, C., Servodidio, V., Sansone, M., Russo, S., Corrado, B., Servodio lammarrone, C., Caprio, M. G., \& Vallone, G. (2018). Use of ultrasound shear wave to measure muscle stiffness in children with cerebral palsy. Journal of Ultrasound, 21(3), 241-247. https://doi.org/10.1007/s40477-018-0313-6

Walton, D. M., Macdermid, J. C., Nielson, W., Teasell, R. W., Chiasson, M., \& Brown, L. (2011). Reliability, standard error, and minimum detectable change of clinical pressure pain threshold testing in people with and without acute neck pain. The Journal of Orthopaedic and Sports Physical Therapy, 41(9), 644-650. https://doi.org/10.2519/jospt.2011.3666

Ylinen, J., Nykänen, M., Kautiainen, H., \& Häkkinen, A. (2007). Evaluation of repeatability of pressure algometry on the neck muscles for clinical use. Manual Therapy, 12(2), 192-197. https://doi.org/10.1016/j.math.2006.06.010 
